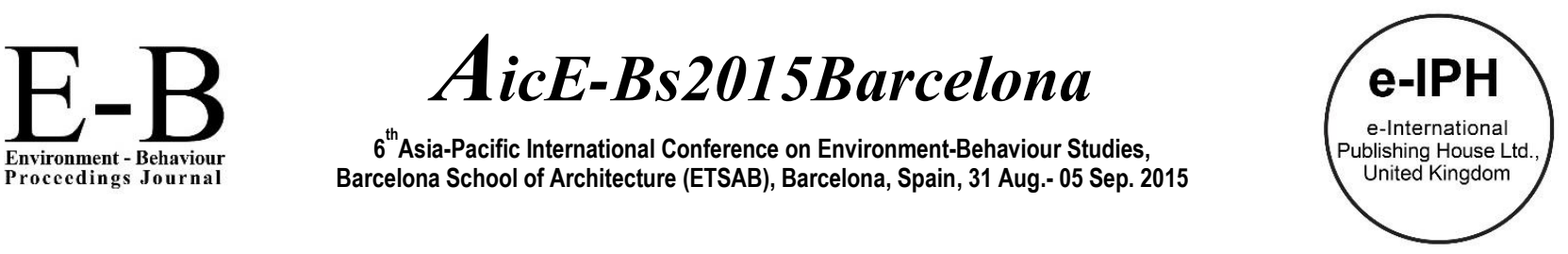

\title{
Cultural Pathology of Double Glazed Windows in terms of Environmental Connectivity Culture in Iran
}

\author{
Nastaran Parsaei a, * , Rana Soleymanpour Asl Navasar a, Maryam Banaei a \\ a Faculty of Architecture, Iran University of Science and Technology, 16846-13114 Tehran, Iran
}

\begin{abstract}
One of the main sustainable products for reducing fuel consumption is a double-glazed window. Despite the positive impacts of these windows in Iran, maybe usage of them has negative effects on environmental connectivity. Environmental connectivity is important in Iranian's culture in different aspects of privacy and nature relatedness that has influenced the architecture of Windows. The aim of this research is to study the cultural pathology of double glazed windows in today's housing of Iran by analyzing Spearman correlation coefficient. Also, we suggest patterns from traditional windows to improve the environmental connectivity culture by focusing on sustainable designing.
\end{abstract}

(C) 2016. The Authors. Published for AMER ABRA by e-International Publishing House, Ltd., UK. Peer-review under responsibility of AMER (Association of Malaysian Environment-Behaviour Researchers), ABRA (Association of Behavioural Researchers on Asians) and cE-Bs (Centre for Environment-Behaviour Studies, Faculty of Architecture, Planning \& Surveying, Universiti Teknologi MARA, Malaysia.

Keywords: double glazed windows, environmental connectivity Culture, Sustainability, Iranian traditional window.

\section{Introduction}

Human and environment interact in many different ways. "Environment" mainly consists of two main parts; namely natural and artificial environment (Ertürk, 1998). Human beings live within and depend on the environment and need it for their survival. For attaining this interaction, the built environment should be in contact with the natural environment by adding nature into the built environment. Also by increasing the harmony and connection between the interior spaces of the built environment and the outdoor. Accordingly windows are an important part of the built environment especially in the houses to provide any connection with the surrounding environment and inhabitants. As Alexander (1979) said in his book that" A window with a "window place" helps a person comes to life. But a room that has no window place, in which the windows are just "holes," sets up a hopeless inner conflict in me which I can't resolve.

Recently in Iran, developments in sustainable technologies that have an important role in reducing energy consumption improved. For instance, Windows technologies for buildings have faced radical changes and technological innovation such as the use of double glazed windows (Fig. 1.). These windows that have significantly improved are one of the best options that control the heat interaction between indoor and outdoor spaces and are being noticed as a key factor in building energy consumption due to the importance of this function, most of the new windows especially double glazed window are designed without

\footnotetext{
${ }^{*}$ Corresponding author. +98-917-737-6170; fax: +9871138357669.

E-mail address: nstrn.parsaei@gmail.com.
}

(C 2016. The Authors. Published for AMER ABRA by e-International Publishing House, Ltd., UK. Peer-review under responsibility of AMER (Association of Malaysian Environment-Behaviour Researchers), ABRA (Association of Behavioural Researchers on Asians) and cE-Bs (Centre for EnvironmentBehaviour Studies, Faculty of Architecture, Planning \& Surveying, Universiti Teknologi MARA, Malaysia.

DOI: http://dx.doi.org/10.21834/e-bpj.v111.198 
considering environmental connectivity in Iran and are not adapted to the culture and lifestyle of people in different regions. It also causes improper usage of these windows. While the connection with the environment is important in Iranian's culture from the different viewpoint of privacy and visual or emotional connection with nature. This culture has influenced the architecture of traditional windows. Windows played an important social, symbolic and climatic role in this land from the past.

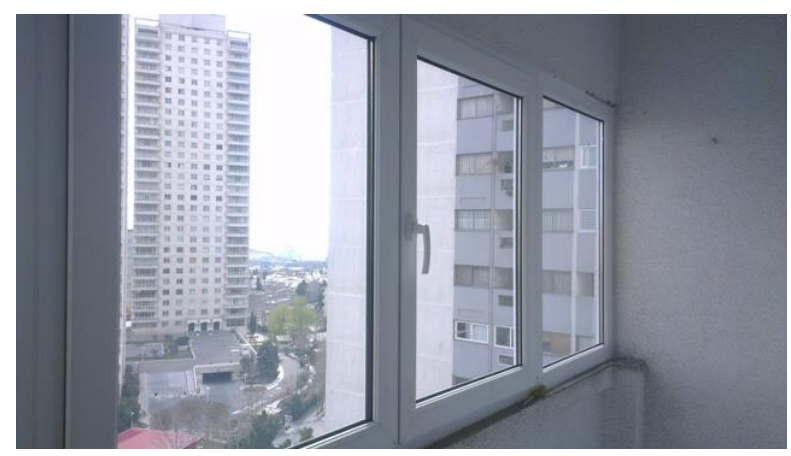

Fig. 1. Double glazed windows.

Sources: Archive of Farad Window Company, (2014).

The aim of this study is to investigate the cultural pathology of double glazed windows in today's housing of Iran by focusing on the environmental connectivity culture of Iran. As traditional windows of Iran have a special design, we can analyze the advantages of the past architecture and make an attempt in order to build compatible environmental structures by improving environmental connectivity culture and focusing on sustainable design. Consequently, the main objective of this study is to explore the possible ways of increasing connectivity with the environment in new windows of contemporary houses. It can happen by studying the sustainability of Windows, environmental connectivity by focusing on privacy and nature relatedness and analyzing the characteristics of traditional windows of Iran.

\subsection{Importance of windows in sustainable discussion and environmental connectivity culture}

Considering Importance of windows in architectural design is the subject of many types of research that clarifies its significance. Kolas (2013) stated "all building facades have windows (i.e., glazing parts) because windows introduce daylight and fresh air and provide a view for occupants. Daylight may enhance comfort and health and has been shown to improve work performance." Kaplan (2001) noted that the functions of windows are to permit access to the sky that allowed the sight to the weather.

According to Joseph (2006), the presences of windows and access to natural daylight have been linked with increased satisfaction upon the users. Natural lighting has some impacts on human health and performance such as; enabling performance of visual tasks, controlling the body's circadian system, enabling critical chemical reactions that affects mood and perception and reducing depression among patients in the hospitals.

In terms of the healing process, Phiri (2003) declared that natural lighting Advantages on the psychological effects to individuals such as the workers and patients. He found that natural lighting had a positive effect on worker's productivity and patients' recovery.

Recently, Sustainable development concerns a wide range of social, scientific, economical and environmental issues (Dondon,'et al', 2012) and especially has influenced the windows design and changing the function of them. Technological innovation such as the use of double and triple glazed units with inert gas filling and invisible low emissivity coatings have significantly improved the insulation properties of windows (Belliard, R., (2014). 
During this transformation although windows have good thermal performance and controlling the microclimate of the houses, the important function of them became weak. New double glazed windows changed the culture of environmental connectivity without paying any attention to the culture of context (Fig. 2). In this field, Rapoport (1983) categorizes cultural values in two types: core and peripheral. Core values are important for the continuity of the culture and society. They are essential in the view of society to itself, and the others view to the society. Commotion in core values causes upsets in the society's equilibrium and may threaten its integrity (Al-Kodmany, 2007).

Hence, windows of buildings are highly associated with the environmental culture that we can use this importance to achieve the new structure of windows in buildings by emphasizing on the sustainable technologies.

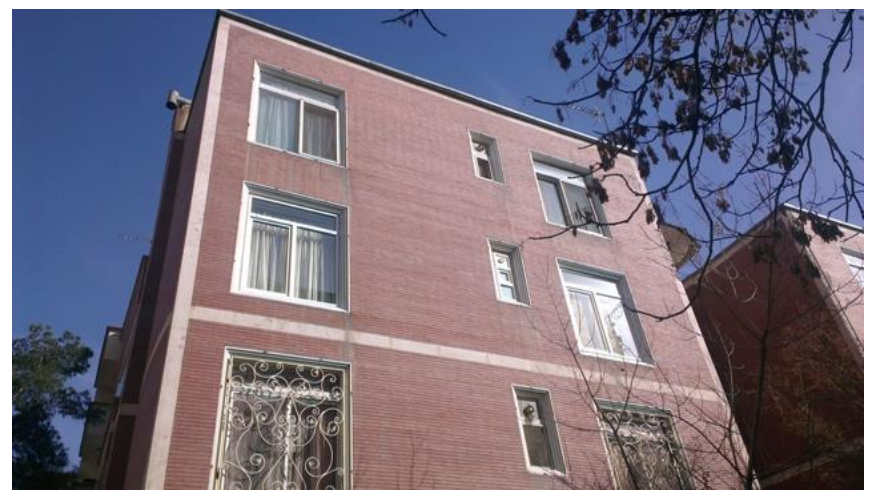

Fig. 2. Double glazed windows used in façade of Iranian house without any attention to the culture Sources: Archive of Farad Window Company, (2015).

\subsection{Traditional windows and Environmental connectivity culture}

Different societies and cultures can have a different idea about some phenomenons like window. In the architecture of various ethnic groups, a window is one of the factors that have significantly contributed to shaping the appearance of residential buildings and also the transmission characteristics of architecture (Parsa, 2011).

In the past, it was not possible to artificially control the quality of the interior environment. Without artificial heating, cooling and lighting households could rely only on the external conditions to create a comfortable environment in their dwellings. In that context, windows were a fundamental mean to mitigate and selectively use the features of an external environment (Contaldo, 2012).

In one research Akbar (2012) opined that traditional windows are not only holes to let light and air get into the room; they are also places through which people communicate with nature, maintain their relationship with neighbor's and resolve their stress. It is where the inside stretches to the outside while maintaining its privacy. He also said Windows play an important role in determining the quality of space and Even though windows are at the edge of the room, they could be the focal point especially in summer; in cold climates they allow access to some sun and in hot climates to some air. While, today windows can no longer be the harbinger of land that they belong.

\subsubsection{Iranian traditional window}

Windows of Iran traditional houses had an important social, symbolic and climatic role in the past. The window was a great interior and exterior element. It was a window to let air and light get in, a communication tool for women with neighbors and alleys, and a representative of the household's identity (Fig. 3.).

In the past, the size and other features of the windows were chosen According to various factors including air temperature, humidity, the amount of required ventilation and other properties of the natural environment. Living in a built closed space without any view and appropriate perspective would be unpleasant and extremely difficult for a long time although it has solved the problem of light and ventilation. 
In Iran, Windows was not considered only as a simple element to meet some initial needs. Like other architectural elements, they played an important role in supporting the spiritual and social needs of individuals, including maintaining the privacy, nature connectivity, diversity and beauty of space (Soltanzadeh, 1996).

In the meantime, maintaining the privacy and nature connectivity are the importance factors in designing traditional window that are retrieved from Iranian culture.

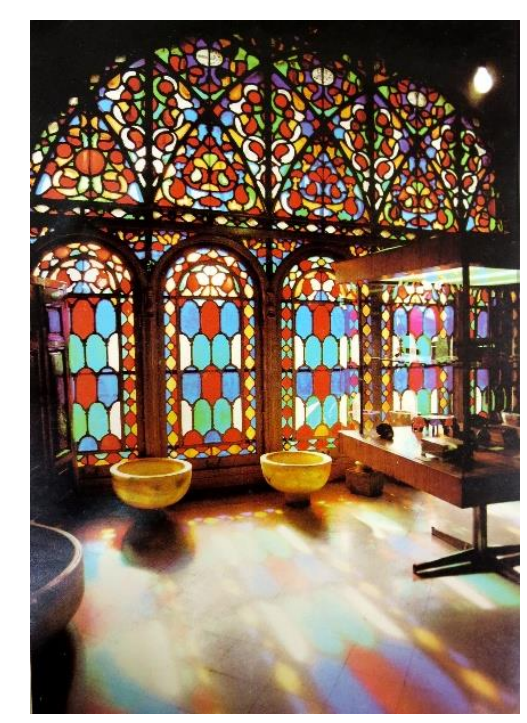

Fig. 3. Windows used in traditional houses of Iran Sources: Ganj Nameh., (2003).

\section{Nature connectivity}

Strong nature relatedness brings happiness to human life and causes ecologically sustainable behavior. Nature relatedness, is an awareness and understanding of all aspects of the natural world, even those that are not aesthetically appealing or useful to human, beside enjoyment of the superficially pleasing facets of nature (Nisbet. \& Zelenski, 2013).

Nature Disconnection has harmful consequences for both human and environmental health, yet it is a regular consequence of the modern lifestyles that often separate people (physically and psychologically) from the natural world (Nisbet. \& Zelenski, 2013). For example Suresh, et al. (2005) reported that views of nature through windows benefited patients recovering from surgery and affected the physical health aspect of individuals.

People like to have control over their environment, and they like having access to fresh air, breezes, and the outdoor environment. These facts are not just casual observations (Borgeson. \& Brager, 2008). The biophilia hypothesis (Kellert \& Wilson, 1993) states that humans are biologically predisposed to be attracted to nature and to depend on nature.

Accordingly, humans have an instinctive need to affiliate with nature that in design in the traditional window of Iran paid more attention to these parameters for achieving the good quality of life (Fig. 4.). 


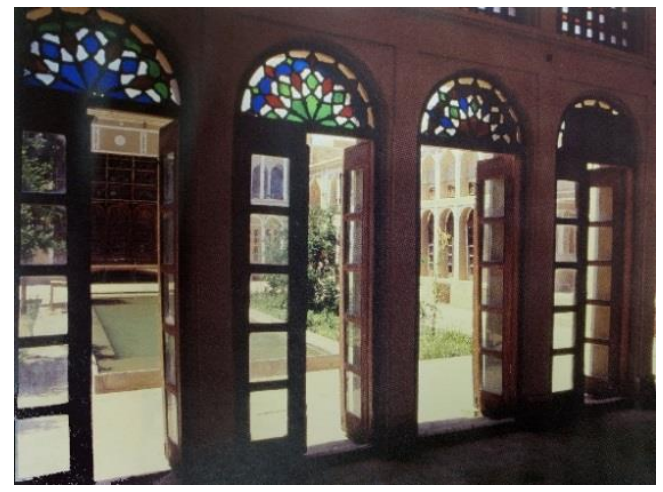

Fig. 4. Windows used in traditional houses of Iranian with a good nature connectivity Sources: Ganj Nameh., (2003).

\subsubsection{Maintaining the privacy}

According to Westin (1967), "Privacy is the claim of individuals, groups, or institutions to determine for themselves when, how, and to what extent information about them is communicated to others. (Shabani, 'et al.', 2011). There is an inherent tendency in human being towards privacy, the most important of which is realized at home (Memarian. Hashemi \& Ranjbar-Kermani, 2011).

In Islam, privacy has been given a holy value and caring for privacy starts with believers themselves. Based on this, a Muslim man must avoid looking other women and a Muslim woman must keep from looking at strange men. Therefore, it can be concluded that the structure of a home, as far as the Islamic culture is concerned, should cater for family and home privacy (Memarian. Hashemi \& Ranjbar-Kermani, 2011).

Like other Islamic domains, Iranian traditional architecture was responsible for the Residents culture and the privacy of individual and his family as maintained in both houses and neighborhoods (Julaihi, Khozaei, 2008).

Hence, this factor have had a great impact on Persian architecture, especially on designing traditional windows and these windows reflected cultural trends.

\subsubsection{Evolution of the Iranian window}

Windows with wooden double-leaves rolling on wooden heels were the most common type.

Different traditional windows of the past can be named and described as the following (table 4):

- Stands Windows: A window that either had the same function in the window and input or have the only difference with the physical characteristics of the door, there was a transparent surface in all or part of its surface. Its most application is in the possibility of communicating with the outside world at a lower level than windows.

- "Orosis are special windows in the Iranian architecture. In most cases, they have Stained glasses that add to the beauty of the house space by creating colored lights. Appropriate light processing has a good and influential effects on human health and comfort." (Habib, Alborzi \& Etessam, 2013)

The lattice surface of them had multiple uses: Reducing the intensity of sunlight and heat, Maintaining privacy of space inside the room, Adding to the beauty of the house space by having stained glasses and creating colored lights. "Appropriate light processing has a good and influential effect on human health and comfort. Intense light hurts the eyes and results in eye strain; on the other hand, faint light causes tiredness, eye strain, headache, and stress.

- Rozan: (Aperture) is an opening in the wall, usually on top, which admits light and provides ventilation as Auxiliary 
elements. It also provides contrast, visual variety, light and shadow, and virtual composition.

- Roshandan and Horno are traditional skylights placed in the ceiling. They allow light into the inner space and provide a view to the sky. They show time by creating a shining area inside space. Also, they display variable light qualities because light enters at different angles and in different directions at different times of the day. They can be used for Adjustment of the heat and humidity.

- Shabak is a kind of lattice window which allows light into inner spaces. It creates visual manifestations of light and at the same time limits visibility". (Habib, Alborzi \& Etessam, 2013)

In the Qajar period and the relationship with the West, changes in the windows appeared, including deformation of the above side of windows and the square changed into round bends, reducing intricacy and using larger glasses. Over time, the intricacy, stained glasses, and Shabak removed, and windows diminished into holes in walls surface. Nowadays, due to the factory construction and mass production, the windows have common features in all cities, climates and different places that are not responsive to the issues of climate and culture. As such, the role of Windows has diminished greatly.

The new window type did not have any structure like the Tabeshbands that are vertical separators and are placed on the openings to allow appropriate light via partial refraction of light to maintain privacy and control the amount of daylighting. The role of Windows diminished greatly.

Therefore, it is essential to identify the parameters that had an influence on designing of traditional windows of Iran as according to culture and human needs and connection with the environment for using to improve a new design of Windows.

\section{Materials and Methods}

\section{Participants}

Sixty-five people participated in this study that was selected by using accidental sampling from university students. Our population was from different cities in Iran such as Tehran, Shiraz, Mashhad, Tabriz and Isfahan with frequencies 29.2, 12.3, $12.3,6.2$ and 4.6 percent respectively. In this study 56.9 percent of participants living in the houses while 41.5 percent is living in apartments. 63.1 percent of the windows in this study were double glazed windows while 36.9 percent were single glazed windows. It shows the high frequency of double glazed windows in dwellings in Iran. We want to evaluate the correlation between double glazed windows and cultural parameters, so we worked on 41 houses with double glazed windows. Also, most of the participants lived on the ground floor (33.8\%), and the most frequent area of houses was $200 \mathrm{~m} 2(12.7 \%)$.

\section{Materials and measures}

This is a Correlational research that explores the relationship between the environmental connectivity culture and double glazed window's response. First the windows were checked in terms of the type, size, direction and level of satisfaction of residents to measure their response according to sustainable and satisfaction issues. Then cultural parameters associated with the environment, such as privacy and nature connectivity were examined by using 5 points Likert Scale. We divided privacy and nature connectivity into smaller items that were enjoying the outdoor, nature light and, etc. For nature connectivity, we used some parameters of a standard questionnaire called (Nisbet, Zelenski \& Murphy, 2009).

The questionnaire was computed by calculating the Cronbach's alpha for 24 items of a questionnaire. The Cronbach alphas were acceptable, being 0.708 . We evaluated the correlation between double glazed windows and cultural parameters by using Spearman's rank correlation coefficient.

\section{Findings}

Tables 1 and 2, show the Mode data for evaluating of each variable in the double glazed windows and nature relatedness culture. Although we studied in different cities in Iran with different climate region, but our results show that they have the same window type these days. Also, it shows that people has the great culture of nature relatedness and privacy. 
Table 1. Mode data for evaluating of each variable in the double glazed windows and nature relatedness culture.

\begin{tabular}{|c|c|c|c|c|c|c|c|c|c|}
\hline & 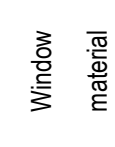 & $\begin{array}{l}\overline{\frac{\pi}{0}} \\
\overline{0} \\
\overline{0} \\
0\end{array}$ & 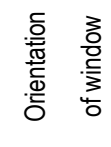 & 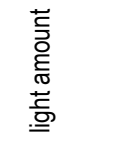 & $\frac{3}{\frac{3}{3}}$ & 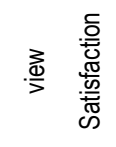 & $\begin{array}{l}\frac{D}{N} \\
\frac{N}{5} \\
\frac{3}{0} \\
\frac{0}{3}\end{array}$ & 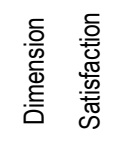 & 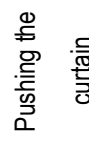 \\
\hline $\begin{array}{l}\text { N Valid, } \\
\text { (Missing) }\end{array}$ & $41,(0)$ & $41,(0)$ & $41,(0)$ & $41,(0)$ & $40,(1)$ & $41,(0)$ & $41,(0)$ & $41,(0)$ & $40,(1)$ \\
\hline Mode & UPVC & Modern & South & High & Neighbourhood & High & High & High & $>6 \mathrm{~h}$ \\
\hline
\end{tabular}

Table 2. Mode data for evaluating of each variable in the double glazed windows and nature relatedness culture.

\begin{tabular}{|c|c|c|c|c|c|c|c|c|c|c|c|c|c|c|c|}
\hline & 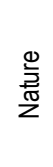 & 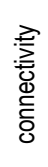 & 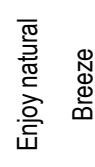 & 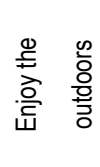 & 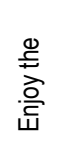 & 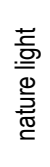 & 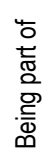 & 罯 & 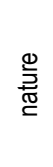 & 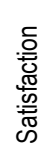 & 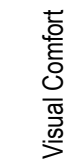 & $\begin{array}{l}\frac{3}{0} \\
\frac{0}{0} \\
\text { se }\end{array}$ & 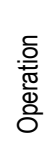 & 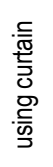 & $\begin{array}{l}\text { ర్ } \\
\mathbb{\$} \\
\mathbb{\Xi}\end{array}$ \\
\hline N Valid, (Missing) & \multicolumn{2}{|c|}{$41,(0)$} & $41,(0)$ & $41,(0)$ & \multicolumn{2}{|c|}{$41,(0)$} & \multicolumn{2}{|c|}{$41,(0)$} & \multicolumn{2}{|c|}{$41,(0)$} & $41,(0)$ & \multicolumn{2}{|c|}{$41,(0)$} & & \\
\hline Mode & \multicolumn{2}{|c|}{ High } & High & High & \multicolumn{2}{|c|}{ High } & \multicolumn{2}{|c|}{ High } & \multicolumn{2}{|c|}{ High } & High & \multicolumn{2}{|c|}{ High } & \multicolumn{2}{|c|}{ High } \\
\hline
\end{tabular}

Fig 5 shows the changes between single and double glazed windows for each cultural variable. All of the changes are not significant. It only shows the level of view satisfaction, nature connectivity, nature connectivity satisfaction, privacy and satisfaction decreased by using double glazed windows, although the sustainability level increased.

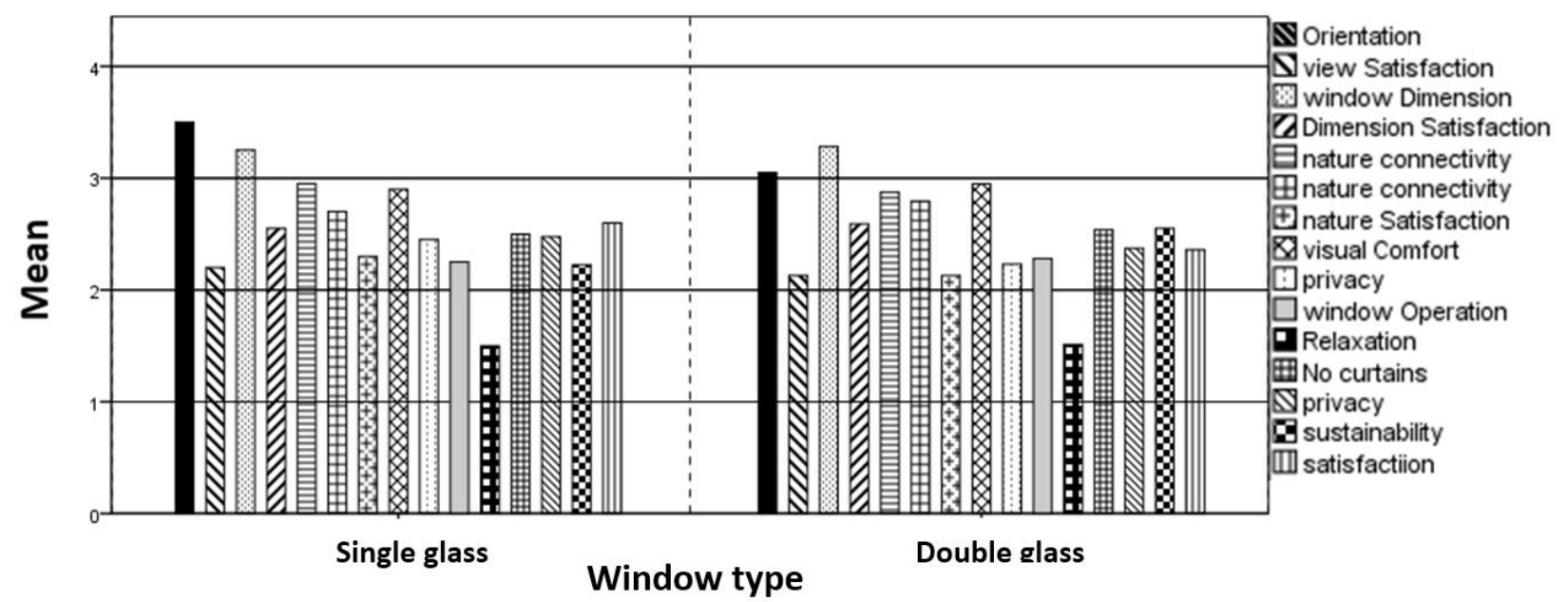

Fig. 5. Changes between single and double glazed windows for each cultural variable

Results show that Spearman correlation coefficient is significant for the hypothesis, and there is a significant correlation between the low level of privacy and connectivity with an inappropriate function of double glazed windows. 
Table 3 shows that there is a significant correlation between Window Dimension, Nature Satisfaction and Window Operation (0.382, $p=0.014 \& 0.352, p=0.026$ respectively). Also, Window Dimension has negative significant correlation with Calmness (0.373., $p=0.016)$. Moreover there is a correlation between Without Curtain, Visual Comfort and Calmness $(0.353, p=0.011$ \& $0.325 p=0.008$ respectively). Also it has negative correlation with privacy $(-0.254 p=0.041)$. View has negative correlation with Calmness and positive one with Nature Satisfaction $(-0.335, p=0.032 \& 0.512, p=0.001$ respectively). Furthermore, View satisfaction has positive correlation with nature satisfaction $(0.780, p=0.000)$. Orientation has positive correlation with Window Operation and negative one with Natural Connectivity $(0.368, p=0.019 \&-0.329, p=0.036$ respectively).

Table 3. Table of variables with a significant correlation ( ${ }^{*}$. Correlation is significant at the 0.05 level (2-tailed). ${ }^{* *}$. Correlation is significant at the 0.01 level (2tailed). $\mathrm{N}: 41$ is for double glazed only, 65 is for all of the windows)

\begin{tabular}{|c|c|c|c|c|c|c|c|c|}
\hline & & 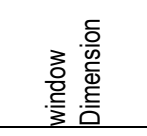 & 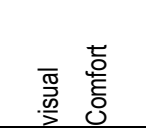 & . & 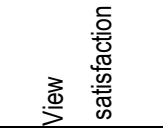 & 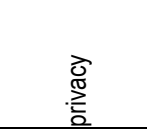 & 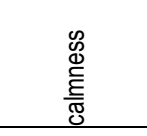 & 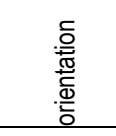 \\
\hline 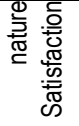 & $\begin{array}{l}\text { Correlation Coefficient, } \\
\text { (Sig. (2-tailed)) - N }\end{array}$ & $\begin{array}{l}.382^{*},(.014) \\
-41\end{array}$ & & & & & & \\
\hline 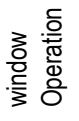 & $\begin{array}{l}\text { Correlation Coefficient, } \\
\text { (Sig. (2-tailed)) -N }\end{array}$ & $\begin{array}{l}.352^{*},(.026) \\
-40\end{array}$ & & & & & & $\begin{array}{l}.368^{*} \\
(.019)-40\end{array}$ \\
\hline 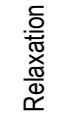 & $\begin{array}{l}\text { Correlation Coefficient, } \\
\text { (Sig. (2-tailed)) - N }\end{array}$ & $\begin{array}{l}-.373^{*} \\
(.016)-41\end{array}$ & & $\begin{array}{l}-.335^{*} \\
(.032)-41\end{array}$ & & & & \\
\hline 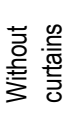 & $\begin{array}{l}\text { Correlation Coefficient, } \\
\text { (Sig. (2-tailed)) - N }\end{array}$ & & $\begin{array}{l}.395^{*},(.011) \\
-41\end{array}$ & & & $\begin{array}{l}-.254^{*},(.041) \\
-65\end{array}$ & $\begin{array}{l}.325^{\star *},(.008) \\
-65\end{array}$ & \\
\hline 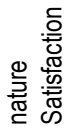 & $\begin{array}{l}\text { Correlation Coefficient, } \\
\text { (Sig. (2-tailed)) - N }\end{array}$ & & & $\begin{array}{l}.512^{* *} \\
(.001)-41\end{array}$ & $\begin{array}{l}.780^{* *},(.000)- \\
40\end{array}$ & & & \\
\hline 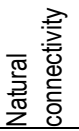 & $\begin{array}{l}\text { Correlation Coefficient, } \\
\text { (Sig. (2-tailed)) - N }\end{array}$ & & & & & & & $\begin{array}{l}-.329^{*} \\
(.036)-41\end{array}$ \\
\hline
\end{tabular}

\section{Discussion}

Changes and ingression of modernism in Iran caused incompatibility between modern lifestyle and people's opinions and culture of Iran (Mohammadi, 2014). The loss of the relationship between modern human and nature is one of these Incompatibles. Whereas in the past connecting to the natural environment while maintaining privacy was an important principle of design, especially in residential design. Today, these important principles have replaced by isolation and feelings of insecurity in homes that can cause a variety of mental illnesses, as Table 3 shows the positive correlation between view, view satisfaction, and nature satisfaction.

This research shows that most of the windows are double glazed with the similar type, and people have nature relatedness and privacy culture (tables 3 ). Spearman correlation results revealed that the size of the window has a significant positive correlation with the performance of the window, but on the other hand it has a negative correlation with a sense of tranquillity. This issue indicates that enlarging the window size is not always helpful and does not lead to a good relationship with the environment. 
There is a significant relation between pulling back the curtain and the sense of privacy. This means that the size and position of the windows do not induce a sense of privacy to the residents. There is also a sense of relief associated with the Existence of the curtains (table 3).

The fact that most people do not have a sense of peace and privacy without curtains on their windows, shows disregarding privacy in the design and manufacture of this type of window frames.

Considering that there is a sense of relief associated with the pulling back the curtain and, on the other hand, there is no connection with the environment and nature in spite of having curtains, reveals that people have to choose between two options connection to nature or having privacy. While, to achieve sustainability considering its principles, including social, economic and environmental all together is essential.

Results show that Spearman correlation coefficient is significant for the hypothesis, and there is a significant correlation between the low level of privacy and connectivity with an inappropriate function of double glazed windows. This article concludes that double glazed windows are not adapted to the culture and lifestyle of people in different regions and causes improper usage of these windows.

Moreover, traditional Windows of Iran considered social and environmental factors that could compliance with the principles of sustainability to the maximum possible extent.

In Table 4 we suggest some aspects of traditional windows with their attributes that can improve today's window design to become more sustainable.

Table4. Traditional windows and its sustainability specifications.

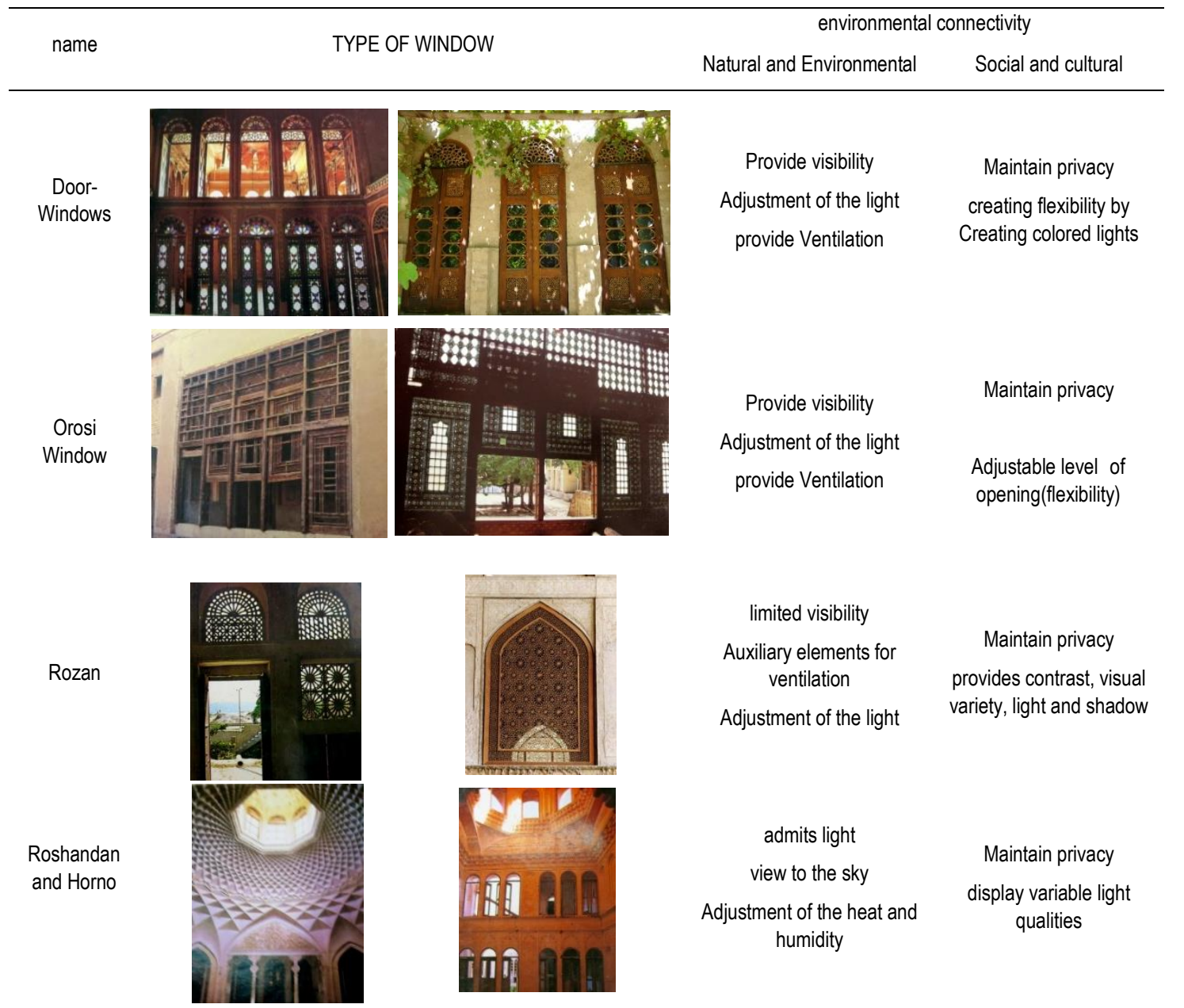




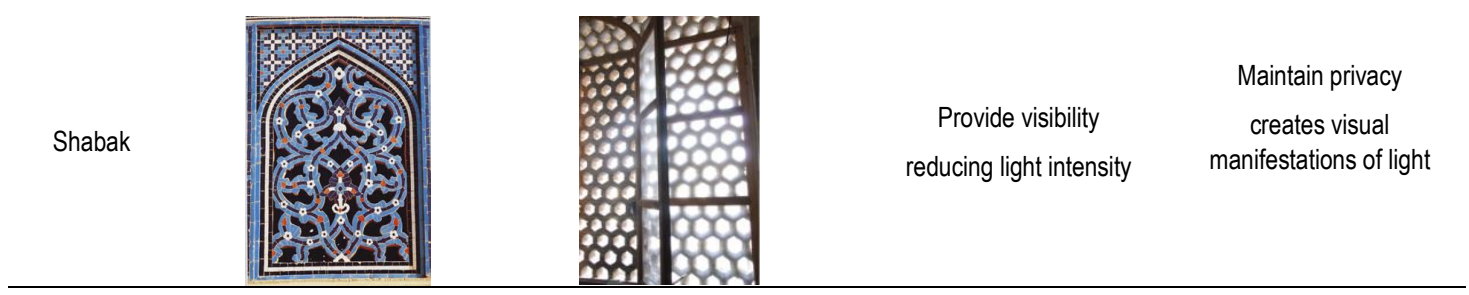

\section{Conclusion}

In this paper, we demonstrated the inability of double glazed windows to meet the psychosocial needs of people, we tried to identify the defects and cultural insufficiency of this kind of modern window and suggest some solutions.

It is the responsibility of contemporary architects to realize the shortages and advantages of imported Products such as double glazed windows and achieve a solution In accordance with peoples Culture in order to be able to respond to the new conditions.

On track to achieve this goal, considering traditional architecture and its components that rooted in cultural and religious characteristics of people are essential and very helpful.

By better understanding and developing ways to restore connections with nature as well as maintaining the privacy, we may be able to foster sustainable behavior as well as promote psychological well-being. By developing strategies to enhance nature relatedness away from mental stress, we may be able to promote human well-being and sustainable behavior concurrently.

\section{References}

Akbar, S., (2012). The Diminishing Role of Windows from Traditional to Modern. . Newcastle, England: Newcastle University.

Alexander, C., (1979). The Timeless Way of Building. New York: Oxford University Press.

Al-Kodmany, KH., (2007). Residential visual privacy: Traditional and modern architecture and urban design. Journal of Urban Design, 4( 3), p1999 .

Borgeson, S., \& Brager, G., (2008). Occupant control of windows: Accounting for human behavior in building simulation. University of California, Berkeley: publication of Center for the Built Environment (CBE).

Contaldo, F, E., (2012). The value of traditional windows in the Mediterranean context. University of Salford, 1(4), p6.

Dondon, Ph., Martiens Dagorette. M., Bulucea, C, A., Marsan. D., (2012). Education to sustainable development: example of a vertical and transversal concrete academic project. Wseas transcactions and advances in engineering eduction, 1.

Erdogan, M., Özsoyl, A, M., (2007). Graduate Students' Perspectives On The Human-Environment Relationship. Journal of Turrkish Science education, 4(2).

Ertürk, H., (1998). Çevre Bilimine Giriş [Introduction to Environmental Sciences]. Bursa: Vipaş Inş.

Ganj Nameh., (2003). Documentation and Research Centre of faculty of Architecture and Urbanism. Tehran, Iran: Publication of Shahid Beheshti University.

Ghazalia, R., Abbasb, M, Y., (2012). Natural Environment in Paediatric Wards: Status and implications. Procedia - Social and Behavioral Sciences, 68 ,173 182.

Habib, F., Alborzi, F., Etessam, S., (2013). Light Processing in Iranian Houses; Manifestation of Meanings and Concepts. International Journal of Architecture and Urban Development, 3(3), P4.

Joseph, A. (2006). The Impact of Light on Outcomes in Healthcare Settings. The Center for Health Design, 2.

Julaihi. W.. Khozaei. F.. \& (2008). Apartment layout and privacy. 2nd INTERNATIONAL CONFERENCE ON BUILT ENVIRONMENT IN DEVELOPING COUNTRIES. 3

Kaplan, R. (2001). The Nature of the View from Home: Psychological Benefits. Environment and Behavior, 33, 507.

Kellert, S, R., Wilson, E, O., (1993). The biophilia hypothesis.Washington, D.C.: Island Press.

Kolas, T., (2013). Performance of daylight redirecting venetian blinds for sidelighted spaces at high latitudes. Trondheim, Norway, The Norwegian Institute of Technology, Department of Architectural Design, Form and Colour, p 335.

Memarian, GH, H,. Hashemi Toghr oljerdi, M,. \& Ranjbar-Kermani, A, M,. (2011). Privacy of house in Islamic culture: A comparative study of pattern of privacy in houses in Kerman. International Journal of Architectural Engineering \& Urban Planning. 1(2), P 8.

Mohammadi, L,. (2014). The effect of modernity on lifestyle. The first International Conference on Economics, Management, Accounting and Social Sciences, Rasht, Iran.

Nisbet, K, E., Zelenski, M, J., Murphy, S, A., (2009). The Nature Relatedness Scale, Linking Individuals' Connection With Nature to Environmental Concern and Behavior. Environment and Behavior, 41(5).

Nisbet, K, E,. \& Zelenski, M, J., (2013). TheNR-6:a new brief measure of nature relatedness. National Center for Biotechnology Information, 1.

Parsa, M, A., (2011) Origin of architecture of window, Research in the concept of window in Persian language and Iranian culture. Housing and Rural Environment,1. 
Phiri,M., (2003). One Patient One Room Theory and Practice: An evaluation of The Leeds Nuffield Hospital University of Sheffield. NHS Research Project, School of Architecture, Arts Tower, Sheffield, pp 120.

Shabani, M, M., Mohd Tahir, M., Shabankareh, H., Arjmandi, H., Mazaheri, F., (2011). Relation of cultural and social attributes in dwelling, responding to privacy in Iranian traditional house. Journal of Social Science and Humanities, Universiti Kebangsaan Malaysia, 5.

Soltanzadeh. H..(1996). Old window of Tehran. Bureau of Cultural Researches, Tehran, Iran.

Suresh, M., Franz, J. and Smith, D., (2005). Holistic Health and Interior Environment: Using the Psychoneuroimmunogical Model to Map Person-Environment Research in Design. The Proceedings of Smart Systems -Postgraduate Research Conference 2005, 188-195.

Belliard, R., (2014). The smart use of glass in sustainable buildings, Glass for Europe. Brussels, 3(4).

Zand Karimi, A., \& Hosseini, B., (2012). The influence of Iranian Islamic architecture on traditional house of Kashan. International Conference, Mukogawa Women's Univ., Nishinomiya, Japan, 1, 6. 